\title{
Overview of Materials International Space Station Experiment 7B
}

\author{
Donald A. Jaworske* and John Siamidis ${ }^{\dagger}$ \\ NASA Glenn Research Center, Cleveland, Ohio 44135
}

\begin{abstract}
Materials International Space Station Experiment 7B (MISSE 7B) is the most recent in a series of experiments flown on the exterior of International Space Station for the purpose of determining the durability of materials and components in the space environment. A collaborative effort among the Department of Defense, the National Aeronautics and Space Administration, industry, and academia, MISSE 7B will be flying a number of NASA experiments designed to gain knowledge in the area of space environmental effects to mitigate risk for exploration missions. Consisting of trays called Passive Experiment Containers, the suitcase sized payload opens on hinges and allows active and passive experiments contained within to be exposed to the ram and wake or zenith and nadir directions in low Earth orbit, in essence, providing a test bed for atomic oxygen exposure, ultraviolet radiation exposure, charged particle radiation exposure, and thermal cycling. New for MISSE 7B is the ability to monitor experiments actively, with data sent back to Earth via International Space Station communications. NASA's active and passive experiments cover a range of interest for the Agency. Materials relevant to the Constellation Program include: solar array materials, seal materials, and thermal protection system materials. Materials relevant to the Exploration Technology Development Program include: fabrics for spacesuits, materials for lunar dust mitigation, and new thermal control coatings. Sensors and components on MISSE 7B include: atomic oxygen fluence monitors, ultraviolet radiation sensors, and electro-optical components. In addition, fundamental space environmental durability science experiments are being flown to gather atomic oxygen erosion data and thin film polymer mechanical and optical property data relevant to lunar lander insulation and the James Web Space Telescope. This paper will present an overview of the NASA experiments to be flown on MISSE 7B, along with a summary of the thermal environment to be expected during the 1 yr mission scheduled for launch in 2009.
\end{abstract}

\section{Nomenclature}

$\begin{array}{lll}\text { BOL } & = & \text { beginning of life } \\ \text { ELC } & = & \text { EXPRESS Logistics Carrier } \\ \text { EOL } & = & \text { end of life } \\ \text { ISS } & = & \text { International Space Station } \\ \text { LEO } & = & \text { low Earth orbit } \\ \text { MISSE } & = & \text { Materials International Space Station Experiment } \\ \text { PECs } & = & \text { Passive Experiment Containers } \\ \text { PICA } & = & \text { Phenolic Impregnated Carbon Ablator } \\ \text { POSS } & = & \text { Polyhedral oligomeric silsesquioxane } \\ \text { ULF } & = & \text { Utilization Flight } \\ x & = & \text { flight attitude, forward } \\ \text { XVV } & = & \text { velocity vector } \\ y & = & \text { flight attitude, level } \\ z & = & \text { flight attitude, down } \\ \alpha & = & \text { solar absorptance } \\ \varepsilon & = & \text { infrared emittance }\end{array}$

\footnotetext{
*Physicist, Space Environment and Experiments Branch, 21000 Brookpark Rd., AIAA Member.

${ }^{\dagger}$ Aerospace Thermal Systems Engineer, Thermal Systems Analysis Branch, 21000 Brookpark Rd., Non-Member.
} 


\section{Introduction}

$\mathrm{M}$ ATERIALS International Space Station Experiment 7 (MISSE 7) is the most recent in a series of MISSEs to fly on the exterior of International Space Station (ISS) ${ }^{1-4}$ MISSE is a collaborative effort among the Department of Defense, the National Aeronautics and Space Administration, industry, and academia to provide a test bed on the exterior of ISS for the purpose of evaluating the durability of materials and components in the low Earth orbit (LEO) environment. MISSE 7 is composed of two suitcase-sized Passive Experiment Containers (PECs), identified as MISSE 7A and MISSE 7B. Hinged on one side, each PEC is closed for launch. Once installed on the exterior of ISS, the PEC is opened. The Naval Research Laboratory has primary responsibility for MISSE 7A, while the Air Force Research Laboratory, NASA, Boeing, other industry collaborators, and academia have experiments on MISSE 7B. Both PECs contain active and passive experiments. Active experiments are designed to interface with the power and communication systems on ISS allowing data to be transmitted back to Earth. Passive experiments are designed for pre- and post-flight evaluation in ground-based laboratories. After approximately $1 \mathrm{yr}$ on ISS, the PECs will be closed and returned to Earth.

The ISS provides a unique platform for LEO exposure. As the ISS has grown, the locations selected to deploy the MISSE hardware has varied. Duration on orbit has also varied. MISSE 1 and 2 were deployed on the Quest Airlock and High Pressure Gas Tank, respectively, in August 2001 and were retrieved in July 2005 for a total of $3.95 \mathrm{yr}$ in LEO. MISSE 3 and 4 were deployed on the Quest Airlock and High Pressure Gas Tank, respectively, in August 2006 and were retrieved in August 2007 for a total of $1 \mathrm{yr}$ in LEO. For these MISSE deployments, the orientation of the hardware was such that, when open, one side of the PEC was facing in the ram atomic oxygen direction while the opposite side of the PEC was facing in the wake direction. MISSE 5 was deployed on the Aft P6 Trunion Pin Handrail in August 2005 and retrieved in September 2006 for a total of $1.1 \mathrm{yr}$ in LEO. For this MISSE deployment, the orientation of the hardware was such that one side of the PEC was solar facing (zenith) and the opposite face was anti-solar facing (nadir). MISSE 6A and 6B were deployed on the Columbus Module in March 2008, in the ram and wake orientation and are scheduled to return in August 2009, with just over 1 yr of exposure in LEO. MISSE 7A and 7B will be deployed on EXPRESS Logistics Carrier 2 (ELC 2) in the late fall of 2009 with the orientation of MISSE 7A in the zenith and nadir directions and the orientation of MISSE 7B in the ram and wake directions.

NASA participation in MISSE 7B is broad and varied, ranging from basic science experiments designed to understand the effects of atomic oxygen and radiation on materials, to specific experiments designed to address materials issues relevant to different aspects of NASA's Constellation Program, Exploration Technology Development Program, and Earth Observing Systems. As part of the NASA participation in MISSE 7B, an extensive thermal model was developed at NASA Glenn Research Center. The model was exercised over a wide range of orbital conditions for the purpose of understanding the thermal environment of MISSE 7B and to identify worst case hot and cold temperature environments. Results from the model were provided to all of the MISSE 7 collaborators.

This paper will describe the thermal model developed for MISSE 7B and will summarize the model results. In addition to identifying the upper and lower temperature extremes for the MISSE 7B hardware, the model also identifies illumination and shadowing conditions encountered in orbit unique to the MISSE 7B location on the ELC. This paper will also summarize the NASA experiments on MISSE 7B, including those aimed at basic science as well as those to be utilized to address program-related space environment durability issues.

\section{Background}

Figure 1 shows the location of ELC 2, i.e., the location of MISSE 7., ${ }^{5,6}$ ISS orbits the Earth in a range of 278 to $500 \mathrm{~km}$, where the main flight attitude is with the ISS $x$-axis towards the velocity vector (XVV). The XVV mode is analogous to an airplane with $x$ forward, $z$ down, and $y$ level. For an orbiting object, beta angle is defined as the angle measured between the sun vector (the plane of the Earth's orbit around the sun) and the plane of the orbiting object. In the case of ISS, beta angle varies from approximately $-75^{\circ}$ to $+75^{\circ}$.

\section{Thermal Analysis Modeling}

The ISS configuration in September 2009 was utilized to start the modeling. The configuration at the time MISSE 7 is installed will be after ELC 1 and ELC 2 are delivered. The ISS configuration in April 2010 was utilized to end the modeling. The configuration at the time MISSE 7 will be removed will include ELC 3 and ELC 4. 


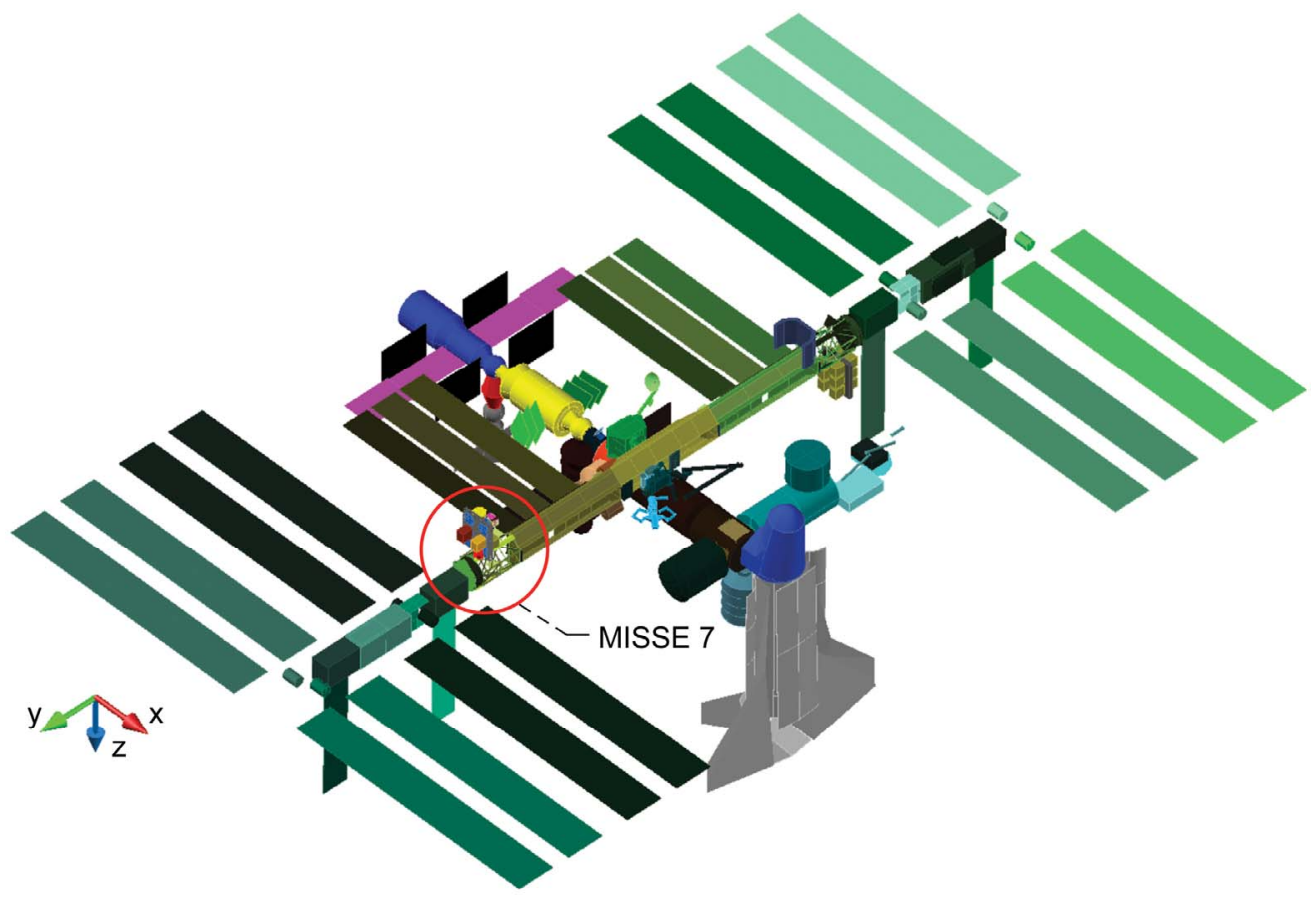

Figure 1. ISS with the MISSE 7 location highlighted.

Two methodologies were utilized for the MISSE 7B thermal analysis, simple and detailed. In the first methodology MISSE 7B was modeled as a simple six-sided box. A Thermal Desktop ${ }^{\circledR}$ model was used with a previously developed ISS Thermal Desktop ${ }^{\circledR}$ model to predict worst case combinations of beta angles and attitude roll, pitch, yaw maneuvers, which in sequence predicts worst case hot and cold orbital heating rates. This model utilized the location of MISSE 7B, two orbital altitudes (278 to $500 \mathrm{~km})$, the beta angle profile timeline $\left(-75^{\circ}\right.$ to $+75^{\circ}$ ) and the orbital attitude and configuration (XVV). In the second methodology, a detailed model of MISSE 7B was used with the ISS Thermal Desktop ${ }^{\circledR}$ model to calculate orbital temperatures of the MISSE 7B experiments to predict worst case hot and worse case cold temperatures. This model utilized the results from the simple model for the worst case hot and cold environments and principal investigator provided electronics dimensions, materials, optical properties, and power dissipation timelines. Figure 2 shows a graphic of the simple and detailed configurations.

The thermal model populated the ELC according to the following Utilization Flight (ULF) manifest plans: ULF3, ULF4 and ULF5. The nearest neighbors in the Thermal Desktop ${ }^{\circledR}$ model were also populated with estimated optical property finishes selected to represent BOL and EOL characteristics. For the MISSE 7B model, the baseplates, electrical boxes, and components utilized the optical properties summarized in Table 1.

Table 1. Selected optical properties utilized in the detailed MISSE 7B thermal model.

\begin{tabular}{ccccc}
\hline \hline Finish & Hardware & $\alpha$ & $\varepsilon$ & $\alpha / \varepsilon$ \\
\hline Chromic anodized aluminum & MISSE baseplates and electronic component boxes & 0.44 & 0.56 & 0.79 \\
\hline \hline
\end{tabular}

Hot and cold orbital heating rates were obtained from the simple model under a variety of conditions, namely with and without the orbiter present, altitudes of 278 and $500 \mathrm{~km}$, various roll, pitch, and yaw values, and beta angle increments of $10^{\circ}$ between $-75^{\circ}$ and $+75^{\circ}$, a total of 27 cases in all. Heating rates were displayed graphically as a function of orbital time (within a 90 min orbit). One case is presented in Fig. 3. Heating rates are summarized on each face of the 6 sided box (nadir, port, ram, starboard, wake, and zenith) as a function of orbital time. The case in Fig. 3 utilizes a pitch of $15^{\circ}$, a roll of $15^{\circ}$, and a yaw of $15^{\circ}$; with BOL optical properties at an altitude of $500 \mathrm{~km}$ without the orbiter attached. The range of heating rates found was between 0 and $620 \mathrm{~W} / \mathrm{m}^{2}$.

From the 27 cases analyzed with the simple model, three were identified as potential worst case hot, and four as potential worst case cold. These worst case hot and cold cases were utilized in the detailed MISSE 7B thermal model and from these cases, the following thermal analysis conclusions were drawn. Worst case hot temperatures 
for nominal operations where the active experiments are powered and functioning are acceptable at beta angles between $+75^{\circ}$ and $-65^{\circ}$, with the majority of experiments on the ram side below $24{ }^{\circ} \mathrm{C}$ for any beta angle and the majority of experiments on the wake side below $50{ }^{\circ} \mathrm{C}$ for any beta angle. Worst case cold temperatures for nominal operations drop to $-45^{\circ} \mathrm{C}$ on the ram side for beta angles between $-65^{\circ}$ to $-75^{\circ}$ and drop to $-40{ }^{\circ} \mathrm{C}$ on the wake side for beta angles between $-65^{\circ}$ and $-75^{\circ}$. Worst case cold temperatures for off nominal operations, where active experiments are not powered, drop below $-60^{\circ} \mathrm{C}$ at beta angles less than $-45^{\circ}$. As summarized in Table 2 for the off nominal case the ram side components drop to a temperature of $-83{ }^{\circ} \mathrm{C}$ and the wake side components drop to a temperature of $-65^{\circ} \mathrm{C}$.
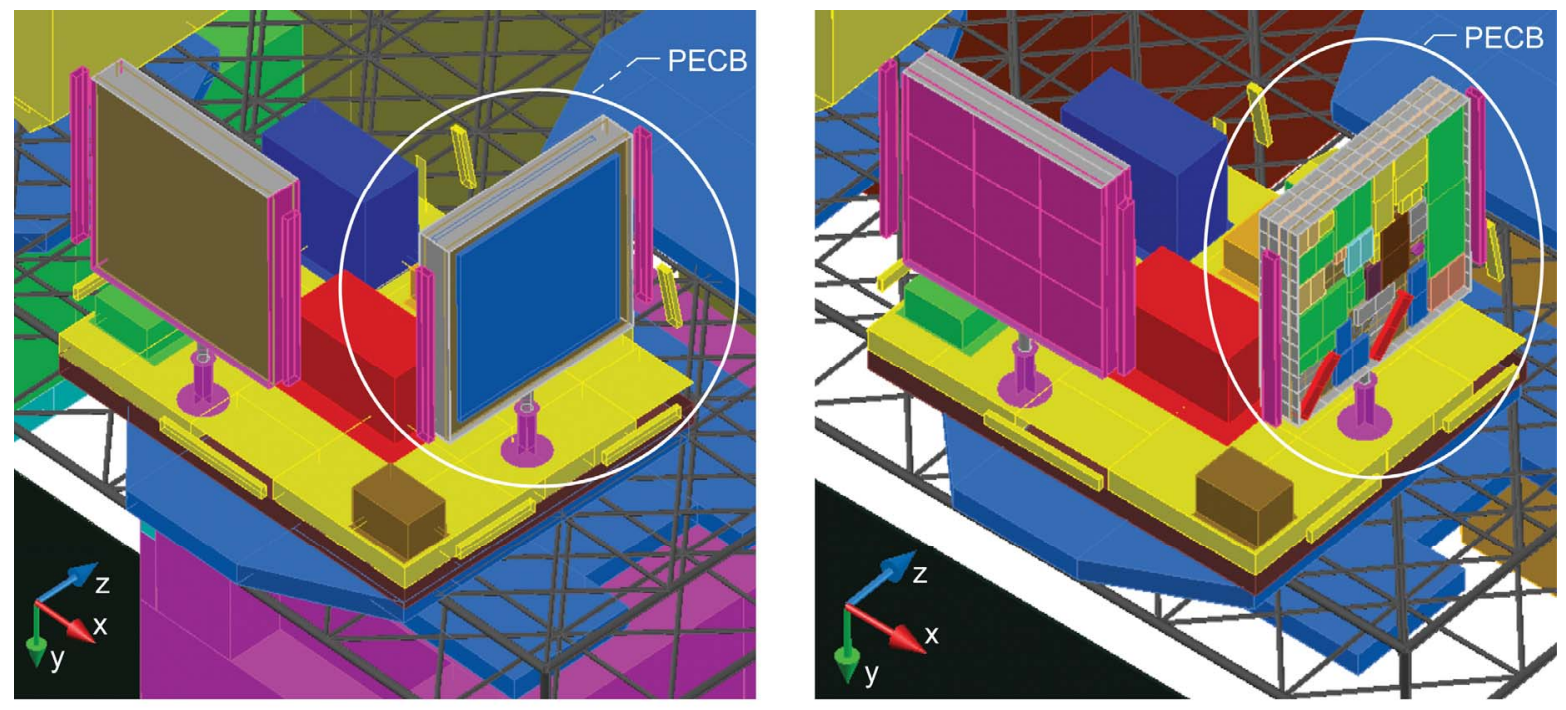

Figure 2. Schematic drawings of the simple and detailed thermal models for MISSE 7B.

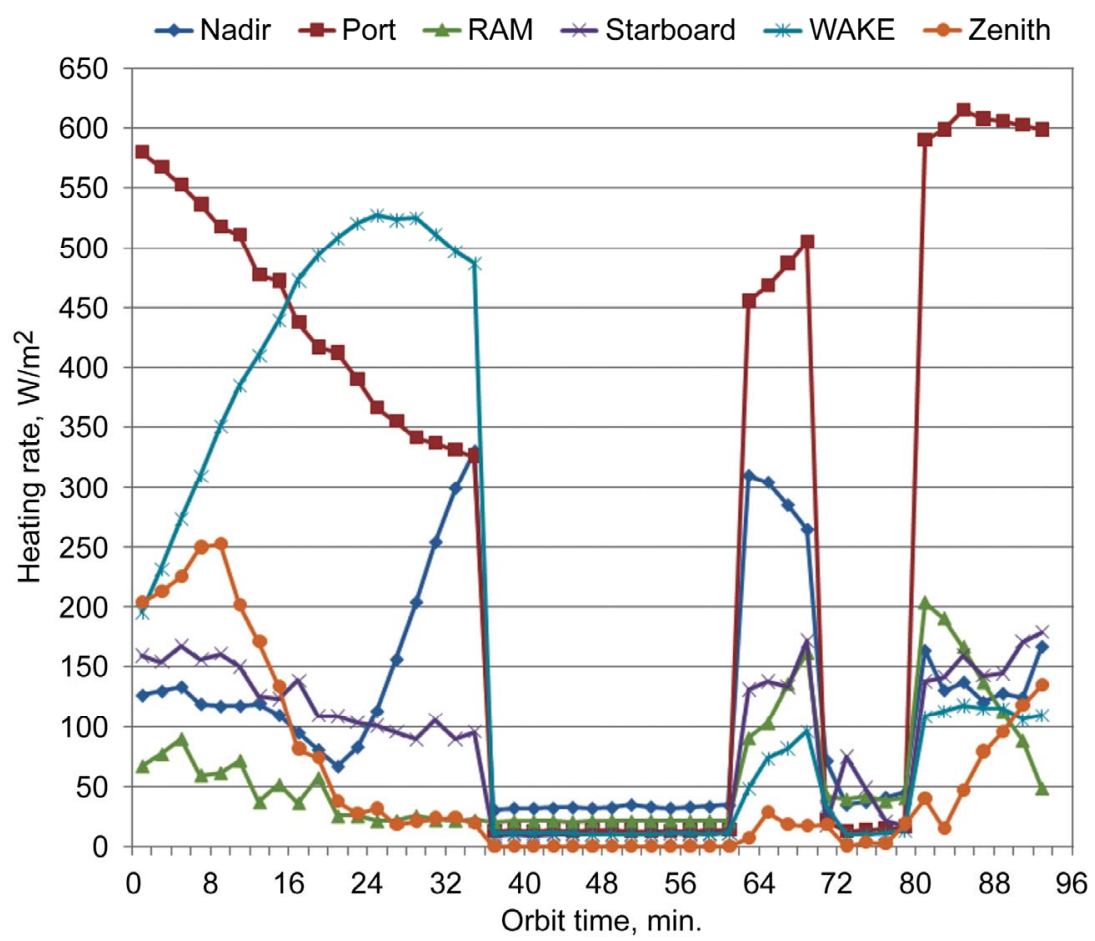

Figure 3. Heating rates as calculated by the simple MISSE 7B thermal model, at BOL, with a beta of $+55^{\circ}$, a roll of $15^{\circ}$, a pitch of $15^{\circ}$, a yaw of $15^{\circ}$, an altitude of $500 \mathrm{~km}$, and without the orbiter attached. 
Table 2. Nominal and off nominal worst case hot and worst case cold temperatures.

\begin{tabular}{|lccc|}
\hline \hline & $\begin{array}{c}\text { Nominal } \\
\text { worst case hot }\end{array}$ & $\begin{array}{c}\text { Nominal } \\
\text { worst case cold }\end{array}$ & $\begin{array}{c}\text { Off nominal } \\
\text { worst case cold }\end{array}$ \\
\hline ram & $24{ }^{\circ} \mathrm{C}$ & $-45^{\circ} \mathrm{C}$ & $-83^{\circ} \mathrm{C}$ \\
wake & $50^{\circ} \mathrm{C}$ & $-40^{\circ} \mathrm{C}$ & $-65^{\circ} \mathrm{C}$ \\
\hline \hline
\end{tabular}

In all cases, the worst case hot temperature scenario was found to be acceptable. For the worst case cold temperature scenarios, beta angles of $-65^{\circ}$ to $-75^{\circ}$ are rare and short in duration, estimated to occur only once in the MISSE 7B mission, and occupying not more than 2 percent of the mission duration. Beta angles of $-45^{\circ}$ to $-75^{\circ}$ also occur seldom, and are equally short in duration, estimated to occur only three times in the MISSE 7B mission, and occupying not more than 5 percent of the mission duration. Adding heaters to the MISSE 7B PEC would have been complex. The unlikely risk of encountering a beta angle of $-45^{\circ}$ to $-75^{\circ}$ simultaneously with an off nominal operating condition was deemed to be an acceptable risk by the principal investigators and no heaters were added to the MISSE 7B PEC to mitigate the risk of a worst case cold scenario.

The heating rate data summarized in the twenty seven cases generated by the simple model also show the impact of shadowing on the MISSE 7 location by other structures on ISS. While in the sunlit portion of the orbit, there are occasional decreases in heating rate indicating a shadowing event. A shadowing event from Fig. 3 is depicted in Fig. 4 with two views of the MISSE 7 location and the surrounding structures on ISS. Looking from the sun at $66 \mathrm{~min}$ into the orbit, the MISSE 7 location is visible, i.e., illuminated. However, looking from the sun at $72 \mathrm{~min}$ into the orbit, the MISSE 7 location is occluded, i.e., shadowed. At $82 \mathrm{~min}$ into the orbit, the MISSE 7 location is no longer shadowed and heating resumes. In short, the heating rate data from the simple thermal model can be utilized to identify multiple shadowing events over the twenty seven cases studied.

\section{Samples Components, and Experiments}

The MISSE series has matured over the years. The suitcase style design has performed well offering principal investigators a platform for sample exposures, yet also offering the ability to protect samples by closing the passive experiment container during transit to and from the exterior of ISS. Indeed, the PEC closes on an o-ring seal and pressure is equalized upon return through the atmosphere utilizing filtered air. The region under the base plate holding the samples has hosted a greater density of electronics as more active experiments were designed and integrated. The test bed now hosts a wide variety of samples, components, and experiments. The most recent in the series, MISSE 7B, has more active experiments than any previous MISSE.
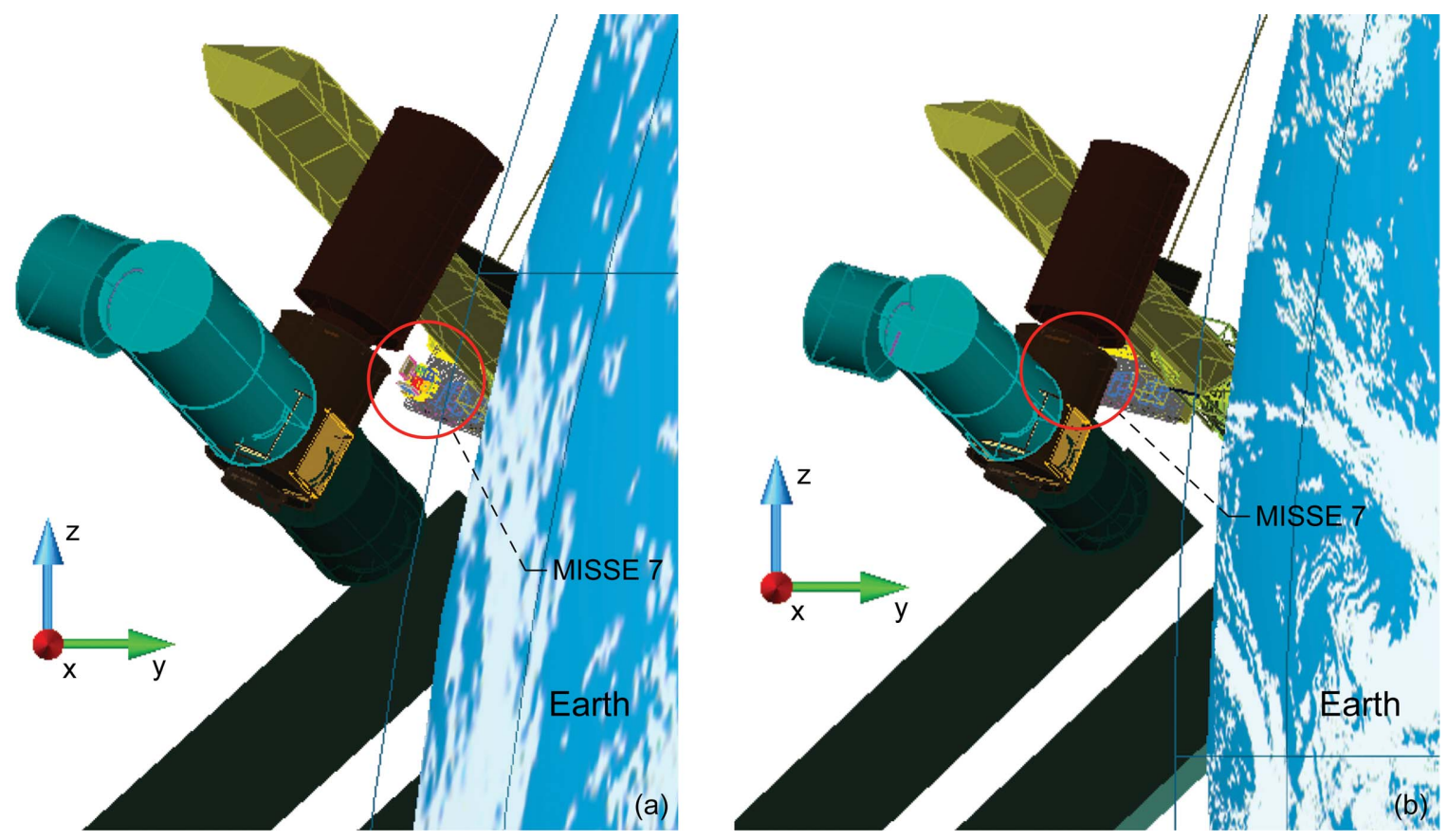

Figure 4. Depiction of a shadowing event as seen from the sun. (a) With the MISSE 7 location illuminated. (b) With the MISSE 7 location occluded. 
Materials, components, and experiments for MISSE 7B were selected that were relevant to ongoing NASA programs. The Constellation Program is chartered to develop the Ares rocket and the Orion crew exploration vehicle. ${ }^{7}$ MISSE 7B is flying selected Orion UltraFlex solar array materials relevant to the Constellation Program to validate their survivability in the LEO environment. Two samples are being flown on the ram side, one composed of front side solar array blanket materials and one composed of back side solar array blanket materials. ${ }^{8}$ Also relevant to the Constellation Program are Orion Low Impact Docking System seal materials to characterize the performance of candidate seal materials when subjected to the synergistic effects of LEO. Being flown on both the ram and wake sides, selected seal materials on MISSE 7B were pretreated with atomic oxygen exposure. Other selected seals materials include samples of RTV silicone and aluminum having the correct mating surface coatings and finishes. ${ }^{8}$ Orion Thermal Protection system materials are also being flown on the ram side of MISSE 7B, to investigate their durability to the synergistic effects of LEO. Phenolic Impregnated Carbon Ablator (PICA) heat shield materials were originally developed for the Stardust probe and the PICA materials are candidate heat shield materials for Orion. ${ }^{9,10}$

The Exploration Technology Development Program is chartered to mature high priority exploration technologies to ultimately enable human exploration of the moon and Mars. ${ }^{11}$ Materials relevant to the Exploration Technology Development Program on MISSE 7B include state-of-the-art orthofabrics for spacesuits. ${ }^{8,12}$ Along with Apollo era fabrics, these samples are being flown to identify and evaluate the effect of long term ultraviolet radiation upon pristine and dust-damaged spacesuit fabric. Fabric samples were characterized extensively before flight utilizing optical, scanning electron, and atomic force microscopy. Damage to the fabric by lunar dust increases the surface area of the fabric's fibers, perhaps increasing the susceptibility to ultraviolet radiation damage. Flying on the wake side of MISSE 7B, the samples should receive little atomic oxygen exposure and ultraviolet radiation exposure much greater than Apollo. Post-flight microscopy is planned to identify the extent of damage. ${ }^{12}$

Polyhedral oligomeric silsesquioxane (POSS) polyimide is relevant to the Exploration Technology Development Program's Dust Mitigation Project and the material is being flown on the ram side of MISSE 7B. ${ }^{8}$ Atomic oxygen exposure generates surface features reminiscent of lotus leaf topology and may offer resistance to lunar dust accumulation. ${ }^{13,14}$

New thermal control coatings such as plasma sprayed beta-alumina coated with lithium silicate nanoclusters, along with ion beam deposited cermet coating standards, are samples relevant to the Fission Surface Power Systems Project and these materials are being flown as active experiments on both the ram and wake sides of MISSE 7B. ${ }^{15,16}$ Recently developed under the NASA Small Business Innovative Research Program, the coatings of beta-alumina doped with zinc oxide are envisioned for use as next generation white thermal control coatings suitable for high temperature use and offer promise for tailoring their coefficient of thermal expansion to match the coefficient of thermal expansion of the underlying substrate. ${ }^{15}$ Developed for solar powered Stirling converters, the cermet coatings are ideal solar absorbers and useful for on orbit calorimetry. ${ }^{16}$

Electro-optical components relevant to the active sensing of $\mathrm{CO}_{2}$ emissions over nights, days, and seasons (ASCENDS) are also flying on MISSE 7B. Flying on the wake side, the objective is to evaluate their long term durability to the low Earth orbit environment. To identify atomic oxygen fluence in real time, atomic oxygen fluence monitors are being flown on both sides of MISSE 7B. As active experiments, the atomic oxygen fluence monitors should provide the space environmental effects community with fluence data via telemetry. Novel micrometeoroid sensors are also flying as part of MISSE 7B.

Experiments for MISSE 7B were also selected that were relevant to space environmental durability science. Much of the fundamental space environmental durability science experiments that are being flown on MISSE 7B are to gather thin film polymer mechanical and optical property data relevant to lunar lander insulation, the James Web Space Telescope, and other applications that utilize polymers in space. The MISSE 7B Polymers Experiment includes samples exposed on the ram and wake sides of MISSE 7B for the purpose of identifying the effects of atomic oxygen and radiation, or radiation alone, on a wide variety of polymers. ${ }^{8}$ Data gathered by the Polymers Experiment will also be important for the predictive modeling of atomic oxygen erosion of polymers. Also included on the ram side of MISSE 7B is an atomic oxygen scattering chamber to provide information on the angular distribution of scattered atomic oxygen with respect to angle of incidence, important for modeling atomic oxygen undercutting of polymers. ${ }^{8}$ Flying on the wake side of MISSE 7B, the Flexural Stress Effects Experiment includes polymers wrapped on mandrels of differing diameter to evaluate the role of stress on polymer cracking. ${ }^{8}$

\section{Conclusions}

MISSE 7 is the most recent in a series of experiments to fly on the exterior of ISS as a test bed for environmental durability studies. Samples, components, and experiments relevant to current NASA programs and of fundamental science interest populate MISSE 7B, one of two PECs comprising MISSE 7. Along with those from NASA, there are 
samples and experiments from the Department of Defense, industry, and academia. Scheduled for launch in the fall of 2009, MISSE 7 will reside on the exterior of ISS for approximately $1 \mathrm{yr}$. Data from active experiments will be retrieved in near-real time via ISS communications. Data from passive experiments will be obtained via post-flight analyses.

A thermal model was developed for MISSE 7B and exercised to identify the upper and lower temperature extremes of the hardware. The model also identified illumination and shadowing conditions encountered in orbit unique to the MISSE 7 location. The model utilized the location on ELC 2, two orbital altitudes, the beta angle profile timeline, and orbital attitude and configuration to predict worst case hot and worst case cold orbital heating rates. The worst case hot and cold heating rate cases were utilized to identify temperature extremes. The worst case hot temperatures for the ram and wake sides were identified as $24^{\circ} \mathrm{C}$ and $50{ }^{\circ} \mathrm{C}$, respectively. The worst case cold temperatures for the ram and wake sides, which occur if the active experiments are not powered, were identified as $-83^{\circ} \mathrm{C}$ and $-65^{\circ} \mathrm{C}$, respectively.

\section{Acknowledgments}

The authors thank NASA's Constellation Program and Exploration Technology Development Program for their interest and support of MISSE 7B. Special thanks are extended to Gary Pippin, Boeing Phantom Works, and Bruce Banks, Alphaport, for all of their helpful discussions and guidance.

\section{References}

${ }^{1}$ Finckenor, M. M., “The Materials On International Space Station Experiment (MISSE): First Results from MSFC Investigations," 44 ${ }^{\text {th }}$ AIAA Aerospace Sciences Meeting and Exhibit, Reno, NV, 2006, AIAA-2006-472.

${ }^{2}$ Robinson, J. A., Evans, C. A., Tate, J. M., and Uri, J. J., "International Space Station Research-Accomplishments and Pathways for Exploration and Fundamental Research," $46^{\text {th }}$ AIAA Aerospace Sciences Meeting and Exhibit, Reno, NV, 2008, AIAA-2008-799.

${ }^{3}$ Evans, C. A., and Robinson, J. A., "Research on the International Space Station-An Overview," $47^{\text {th }}$ AIAA Aerospace Sciences Meeting, Orlando, FL, 2009, AIAA-2009-86.

${ }^{4}$ Jenkins, P., et al., "MISSE-7: Building a Permanent Environmental Testbed for the International Space Station,"

Proceedings of the 9th International Space Conference Protection of Materials and Structures From Space Environment, Toronto, Canada, 2008, (submitted for publication).

${ }^{5}$ National Aeronautics and Space Administration, "Overview of Attached Payload Accommodations and Environments on the International Space Station,” NASA/TP-2007-214768, NASA Johnson Space Center, Houston, TX, Sep. 2007.

${ }^{6}$ Attached Payload Interface Requirements Document —EXpedite the PRocessing of Experiments to Space Station (EXPRESS) Logistics Carrier Cargo Interface Requirements, SSP 57003-ELC, Apr. 2008.

${ }^{7}$ National Aeronautics and Space Administration, "Exploration Systems Architecture Study—Final Report," NASA/TM2005-214062, NASA Headquarters, Washington, DC, Nov. 2005.

${ }^{8}$ de Groh, K. K., Banks, B. A., Dever, J. A., Jaworske, D. A., Miller, S. K., Sechkar, E. A., and Panko, S. R., "NASA Glenn Research Center's Materials International Space Station Experiments (MISSE 1-7)," NASA/TM-2008-215482, Dec. 2008.

${ }^{9}$ Tran, H. K., Johnson, C. E., Rasky, D. J., Hui, F. C. L., Hsu, M., and Chen, Y. K., "Phenolic Impregnated Carbon Ablators (PICA) for Discovery Class Missions," $31^{\text {st }}$ AIAA Thermophysics Conference, New Orleans, LA, 1996, AIAA-96-1911.

${ }^{10}$ Milos, F. S., and Chen, Y.-K., "Ablation and Thermal Response Property Model Validation for Phenolic Impregnated Carbon Ablator," 47 $7^{\text {th }}$ AIAA Aerospace Sciences Meeting, Orlando, FL, 2009, AIAA-2009-262.

${ }^{11}$ Moore, C. L., and Peri, F., "The Exploration Technology Development Program," 45 ${ }^{\text {th }}$ AIAA Aerospace Sciences Meeting and Exhibit, Reno, NV, 2007, AIAA-2007-136.

${ }^{12}$ Gaier, J. R., McCue, T. R., Clark, G. W., Rogers, K. J., and Mengesu, T., "Pre-Flight Characterization of Samples for the MISSE 7 Spacesuit Fabric Exposure Experiment," (submitted for publication).

${ }^{13}$ Wohl, C. J., Belcher, M. A., Ghose, S., and Connell, J. W., "Oxygen Plasma Modification of POSS-Coated Kapton HN Films," SAMPE Conference, Long Beach, CA, 2008.

${ }^{14}$ Cheng, Y. T., et al., "Effects of Micro and Nano-Structures on the Self-Cleaning Behavior of Lotus Leaves," Nanotechnology, Vol. 17, 2006, pp. 1359-1362.

${ }^{15}$ Jaworske, D. A., Dever, J. A., and Deshpande, M. S., "Initial Evaluation of White Thermal Control Paints Incorporating Lithium Silicate Chemistry," 48th AIAA/ASME/ASCE/AHS/ASC Structures, Structural Dynamics, and Materials Conference, Waikiki, HI, 2007, AIAA-2007-2200.

${ }^{16}$ Jaworske, D. A., and Raack,,T., “Cermet Coatings for Solar Stirling Space Power,” Thin Solid Films, Vol. 469-470, 2004, pp. 24-30. 